\title{
UN CICLO MITOLÓGICO TARDÍO DE LA PINTURA SEVILLANA: LA HISTORIA DE PERSEO, POR ESCOBAR
}

\author{
POR
}

\author{
JUAN LUIS GONZÁLEZ GARCÍA
}

\begin{abstract}
This paper deals with the mythological series of Perseus signed in 1662 by the Sevillian master Escobar. Several renaissance precedents in Seville are analysed, together the likely sources that contributed to the composition or the erudite reading of these picture. This background includes some plays by Lope de Vega and Calderón de la Barca. A number of prints engraved by Bernard Salomon and Antonio Tempesta from, which Escobar drew his inspiration are also discussed.
\end{abstract}

Las pinturas españolas de tema mitológico, numerosas durante el Renacimiento, disminuyen abiertamente en las colecciones privadas desde mediados del siglo xvir, como consecuencia de un cambio de sensibilidad que afecta en igual medida a otros géneros pictóricos. Así parece confirmarlo el reciente estudio llevado a cabo por Kinkead sobre unos doscientos inventarios sevillanos fechados entre 1650 y 1699, donde entre el millar corto de cuadros citados sólo se cuenta una decena de obras mitológicas ${ }^{1}$. Dichos cambio, que no nos corresponde analizar aquí, junto con otras motivaciones ilustradas por López Torrijos ${ }^{2}$, hacen que merezca la pena informar de cualquier hallazgo que pueda arrojar alguna luz sobre el gusto por lo mítico en la sociedad española de la segunda mitad del xvIr. En nuestro caso, nos ocupamos de un ciclo heroico hoy perteneciente a una colección particular segoviana.

La serie consta de tres lienzos apaisados de dimensiones análogas $(163 \times 115 \mathrm{~cm})$ y trama gruesa y abierta. No parecen haber sido restaurado nunca, por lo que muestran las acostumbradas pérdidas de pigmento en los márgenes, algunos rayados accidentales y un aspecto amarillento en su conjunto. Dichos cuadros representan otros tantos episodios de la vida de Perseo, mítico héroe de la antigüedad clásica cuyas empresas fueron narradas, entre otros, por Ovidio en sus Metamorfosis. A modo de tituli, en dos de ellos se advierten sendas descripciones en un latín no muy pulido de los hechos correspondientes, ideadas, sin duda, por el propio comprador, demos-

\footnotetext{
1 Kinkead, D., "Artistic inventories in Sevilla: 1650-1699", en Boletín de Bellas Artes, 17, 1989, pp. 117-78.

2 López Torrijos, R., La mitología en la pintura española del Siglo de Oro, Madrid, 1985. De especial utilidad para nuestro trabajo han sido las pp. 35-54, 231-42.
} 
trando un interés aclaratorio y erudito que, como veremos, no sólo remite al texto ovidiano, sino también a otras obras mitográficas y literarias de la época.

El valor de documento o curiosidad de este ciclo pictórico se acrecienta con el nombre de su autor y el año en que fue pintado. El tercero de los cuadros de la serie está firmado y fechado en la esquina inferior izquierda con la inscripción Escobar (rúbrica) fecit año 1662 (Fig. 1). Considerando lo avanzado de la datación, sorprende el estilo arcaizante de este artista, característico del último manierismo sevillano, superado dos o tres décadas atrás. Su modesta técnica de pintor local, poco ajustada al género heroico, se ve aún más «envejecida» por la copia literal de estampas de la segunda mitad del siglo xvI, ofreciendo una imagen atípica para un autor contemporáneo de Murillo. En este caso, tal vez pudiera tratarse de uno de sus discípulos, Alonso de Escobar, aludido por Ceán Bermúdez en su Diccionario, del cual dice que "procuró imitar su estilo" y que vivió «en Sevilla a fines del siglo XVII" ${ }^{3}$. Sin embargo, un joven imitador que viera pintar, en estos años, algunas de las principales series del maestro, sus mejores Inmaculadas y varios de sus famosos cuadros de tema infantil, probablemente estaría más cerca de la pincelada clara y vaporosa de su presunto modelo que de la rigidez tardomanierista dominante en la Historia de Perseo. Creemos, por tanto, que este artista, del que se desconocen otras obras, debía de ser un pintor formado a comienzos del siglo, de edad ya avanzada cuando ejecutó la serie y, en consecuencia, apegado a unas fórmulas retardatarias que se veía incapaz de abandonar.

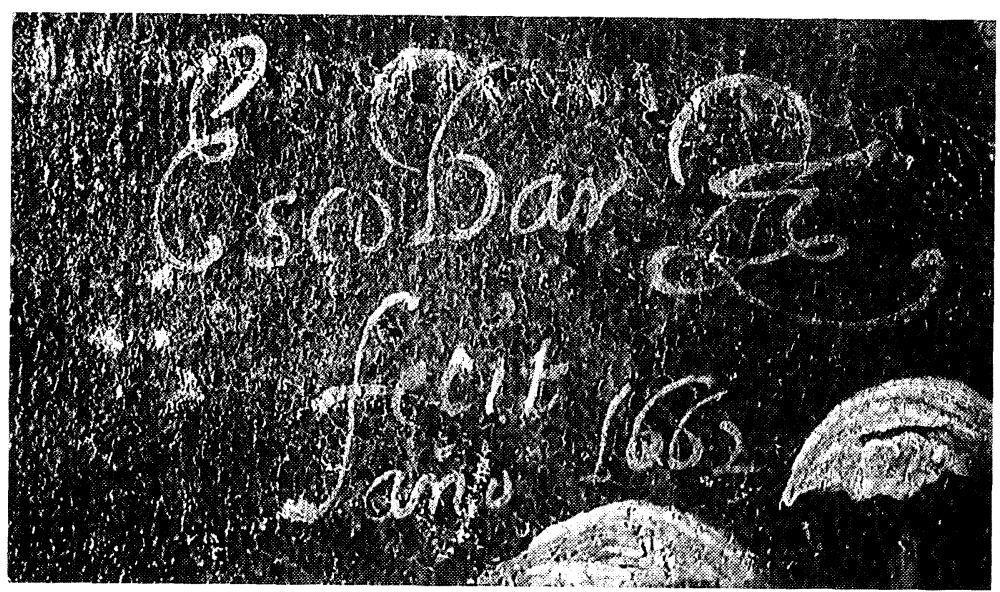

Fig. 1. Firma de Escobar, en su cuadro Catasterismo de Perseo y Andrómeda. Segovia, colección particular.

Ciertos protocolos sevillanos publicados por López Martínez mencionan dos nombres que reúnen estas condiciones, con fechas próximas entre sí. El registro más antiguo corresponde a 1632, fecha en que Pablo Legot nombra como tasadores del retablo mayor de la iglesia de San Salvador, que él mismo "tomo a su cargo de dorar estofar pintar y encarnar" ${ }^{4}$, a los maestros pintores Juan Bautista de Escobar y Pedro Calderón de Alcedo. En 1635 se hace referencia a un Benito de Escobar, "pintor de ymagineria", y a su mujer, ambos vecinos en la colación de Santa Ana, en Triana, que se obligan a devolver un préstamo de 220 reales al doctor Mateo de Espejo

\footnotetext{
3 Cean Bermudez, J. A., Diccionario histórico de los más ilustres pintores de las Bellas Artes en España, vol. 2, Madrid, 1800, p. 30. Ésta es la opinión de López Torrijos, R., o.c., pp. 241 s., 413, que cita las dos primeras pinturas del ciclo.

4 López Martínez, C., Notas para la Historia del Arte. Desde Martínez Montañés hasta Pedro Roldan, Sevilla, 1932 , p. 188.
} 
Valenzuela ${ }^{5}$. Hechas estas puntualizaciones y, como es evidente, dado que sólo disponemos del apellido del pintor, cualquier atribución más concreta debe permanecer, por el momento, dentro de lo hipotético.

Como hemos dicho indicado más arriba, Escobar se sirvió de estampas para componer su serie. Estas proceden, en su mayor parte, de alguna de las ediciones de Lyon de las Metamorfosis grabadas por Bernardo Salomón para el impresor Jean de Tournes, en francés (1557) y en italiano (1559 y 1584) ${ }^{6}$. Las distintas ilustraciones son interpretadas por el sevillano con una literalidad casi absoluta, adornada con unas pocas soluciones personales y, sobre todo, con detalles tomados de varias láminas de las Metamorfosis (Amberes, 1606) ${ }^{7}$ y la primera serie de Los doce meses (Roma, 1599) ${ }^{8}$ de Antonio Tempesta.

Los precedentes temáticos de las pinturas hay que buscarlos en dos de los mayores alardes de erudición mitológica en la Sevilla renacentista: El Banquete de los dioses, techo anónimo de la Casa de Pilatos, y la decoración pictórica de la popa de la Galera Real de Don Juan de Austria. Examinaremos en primer lugar el lienzo de la afamada casa del duque de Alcalá. Aquí, el motivo principal, en forma de círculo, deja libres cuatro ángulos que se corresponden con cada una de las esquinas del techo. En el primero de estos ángulos aparece Perseo, con la espada y los talares de Mercurio, llevando el escudo con la cabeza de Medusa, «en una actitud claramente apotropaica", a decir de Lleó ${ }^{9}$, como dispuesto a enfrentarse al cetáceo que amenaza a Andrómeda. Por su parte, Juan de Mal Lara, en el complejísimo programa simbólico de la Galera Real, condensa esta presencia guardiana y protectora bajo el lema Domat omnia virtus (Todo lo vence la virtud), poniendo a Perseo como ideal de capitán virtuoso «que por parte de la prudencia y afabilidad le uiene que en Palas, y Mercurio se declaran, vence todos los que se le ponen por delante, leuantando de por medio a su padre jupiter, que es el tendimiento Diuino en todas las cosas para tratar negocios tan arduos» ${ }^{10}$. A manera de lección moralizante, el texto clásico transforma su sentido original con arreglo a la exégesis mitográfica del siglo xvI, cuyo gusto por el alegorismo cristianizado se acentuará tras la Contrarreforma.

Así, la pauta que nos proponemos seguir para analizar esta serie de la Historia de Perseo intentará valerse, en la medida de lo posible, de los escritos coetáneos que pudieran tomar parte en su concepción e interpretación, o que determinaron, de una manera natural, el ambiente en el que fue proyectada.

El ciclo da comienzo con el momento en el cual Perseo decapita a Medusa (Fig. 2). La escena está elaborada a partir de la viñeta correspondiente de las citadas Metamorfosis de Bernardo Salomón ${ }^{11}$ (Fig. 4), pero sustituyendo el agreste fondo original por un jardín palaciego extraído de la lámina de Abril grabada para la serie de Los doce meses (Fig. 5). Esta importante variación no atiende tan sólo a razones estéticas. Según cuenta Boccaccio en su Genealogía de los dioses paganos ${ }^{12}$, Medusa tenía unos hermosísimos cabellos de oro por cuyo esplendor sedujo a Neptuno, quien la poseyó en el templo de Minerva. La diosa, irritada por la profanación de su santuario, mudó las guedejas de Medusa en serpientes y le otorgó el poder de petrificar a todo aquel que la

\footnotetext{
5 Idem, Notas para la Historia del Arte. Arquitectos, Escultores y Pintores Vecinos de Sevilla, Sevilla, 1928, p. 38.

6 Reproducimos las ilustraciones de la edición italiana de 1559 (La vita et metamorfoseo d'Ovidio), idénticas a las de 1557 y 1584.

7 Tempesta, A., Metamorphoseon sive transformationvm ovidianarvm libri qvindecim..., Amberes, 1606.

8 Idem, Menses XII anni solaris, Roma, 1599.

9 Lleó Cañal, V., Nueva Roma: Mitologia y Humanismo en el Renacimiento sevillano, Sevilla, 1979, p. 50.

10 Mal Lara, J. de, Descripción de la Galera Real del Sermo. Sr. D. Juan de Austria, Sevilla, 1876, pp. 42 s.

11 Ovidio, La vita et metamorfoseo..., Lyon, 1559, p. 74.

12 Boccaccio, G., Genealogie..., París, 1511, ff. 74 v.-5. Sobre la trascendencia de los manuales mitográficos de Boccaccio, Conti y otros vid. Seznec, J., Los Dioses de la Antigüedad en la Edad Media y el Renacimiento, Madrid, 1983, pp. 185-210.
} 
mirase. Conforme a la tradición evemerista, para Boccaccio la dorada cabellera medusina significa que era rica y poderosa, y Perseo, al cortarle la cabeza, la desposeyó de los bienes en que radicaba su vida y su poder. Junto con sus otras hermanas Górgonas, Esteno y Euríale, Medusa habitaba un palacio en la costa sudoeste de España y, verosímilmente, es su jardín lo que Escobar estaría representando en esta pintura. Las ligeras - aunque evidentes- alteraciones sobre el modelo de Tempesta a duras penas disimulan su procedencia espuria, si bien el retirado bosquecillo de frutales, los macetones con flores y, especialmente, la rosaleda del primer término, evocan con su presencia el mundo meridional.

Otra recopilación harto divulgada, la Mitología de Natale Conti ${ }^{13}$, ampliada por su autor en 1616, recoge el comentario de Boccaccio y lo desarrolla, equiparando a Medusa con la lujuria y los placeres mundanos, que hacen desatender el culto a la divinidad y vuelven como piedras -esto es, inútiles- a los hombres. Por eso resulta indispensable la ayuda de Palas, diosa de la sabiduría, que encamina a Perseo para dar muerte a Medusa, igual que la gracia de Dios, iluminándonos con su doctrina, evita que sucumbamos a la tentación. La explicación más penetrante la ofrece, sin embargo, un traductor y comentador de las Metamorfosis, Pedro Sánchez de Viana, en sus Anotaciones ${ }^{14}$ de 1589 . Al pecado de la lujuria añade el de la soberbia "sobre todos los vicios aborrescida, como madre de ingratitud fuente de do se divina toda maldad». En efecto, Medusa, envanecida por su belleza, es como quien menosprecia los favores recibidos de Dios, $\mathrm{y}$, como aquélla, "sera de su Magestad despojado de todo bien, y castigado con todo mal».

A causa, en fin, de su inmoralidad, la Górgona termina degollada por Perseo, y así se muestra, con la cabeza cercenada, tanto en el lienzo de Escobar como en la ilustración de Salomón. El pintor sevillano remeda, con variantes, la coraza anatómica de tipo helenístico que viste Perseo, suprimiendo los lambrequines e incorporando diversos motivos tomados de la composición del mismo asunto realizado por Tempesta ${ }^{15}$ (Fig. 6). Obviamente, esta edición de las Metamorfosis, mucho más difundida que las de Lyon, no aconsejaba la copia explícita de sus láminas so pena de revelar su origen de inmediato, y se prefirió su aprovechamiento como fuente complementaria.

De este modo, Escobar convierte el manto de Perseo en una especie de colobium o túnica corta, visible bajo las launas flexibles que penden de los hombros y la cadera. El casco de Hades, con penacho y sujeto por unas carrilleras, o el alto calzado a la griega, están subordinados asimismo a la obra de Tempesta. Lleva, en un lateral, el escudo bruñido de Minerva, "que se entiende la sabiduria, o prudencia», en palabras de Pérez de Moya ${ }^{16}$, las cuales no son sino un estricto trasunto del Comento de Eusebio del Tostado ${ }^{17}$. Una vez más, se nos está advirtiendo que "la virtud sola que es esfuerço de coraçon no vence los temores, si no tiene prudencia»; por ello Perseo "como varon virtuoso se cubrio del escudo de Minerva", es decir, "se abroquelo con la prudencia para no ver a Medusa" ${ }^{18}$. La espada de Mercurio, aún manchada de sangre, es el arma de la elocuencia ${ }^{19}$, que vence, junto con la sabiduría, las «dificultades que se han de offrescer en el discurso del camino de la vida, y al cabo della ser coronada con la corona que se deue en virtud de Christo señor nuestro, al que ouiere peleado, y vencido, como valeroso soldado" 20 . Esta reflexión de Sánchez de Viana precisa el significado de la inscripción latina que acompaña

\footnotetext{
13 Conti, N., Mythologiae sive explicationis fabvlarvm librim decem..., Padua, 1616, pp. 390 ss., 424.

14 Sánchez de Viana, P., Anotaciones sobre los quinze libros de las Transformaciones de Ovidio. Con la Mithologia de las fabulas, y otras cosas, Valladolid, 1589, f. $97 \mathrm{v}$.

15 Tempesta, A., Metamorphoseon..., o.c., f. 41. A su vez, Tempesta se inspira directísimamente e las susodichas Metamorfosis enriquecidas por Bernardo Salomón.

16 Pérez de Moya, J., Philosofia secreta, Madrid, 1585, f. 211 v.

17 Madrigal, A. de, Comento de Eusebio, lib. 5, Salamanca, 1507, f. 163. Vid. también Boccaccio, G., o.c., ff. 89 s.

18 Pérez de Moya, J., o.c., ff. 212 s.

19 Vid., por ejemplo, Ovidio, Metamorphoseos Vulgare, Venecia, 1517, f. 31.

20 Sánchez de Viana, P., o.c., f. 101v.
} 
a la pintura: Persevs occidit colvbros ferroqve Medvsam, istivs ABSCISSVM Gloria magna CAPVT (Perseo mató con la espada a las serpientes y a Medusa, su cabeza separada con gran gloria), pues sin «la sabiduria, y sutileza de ingenio, buena maña, y orden... ninguna cosa digna de gloria se alcanza" ${ }^{21}$. El deseo de la fama, de acuerdo con otra traducción española de las Metamorfosis $^{22}$, guía al hombre valeroso en las grandes empresas, lo cual, desde una lectura cristianizada, se identifica con la promesa de salvación que aguarda al miles Christi.

Pegaso, nacido del cuello seccionado de la Górgona, alude a dicha fama de las hazañas ${ }^{23}$, alada y veloz como el célebre caballo. Fue concebido en el templo de Minerva por Medusa y Neptuno, cuya efigie, sobre unos surtidores en forma de hipocampos, remata la fuente de la derecha del cuadro, algo agrandada con respecto al original de Tempesta. Surge del cuello de $\mathrm{Me}$ dusa porque, a juicio del Tostado, la muerte de ésta «era manera de guerra peligrosa en la qual el vencedor gana grande gloria» ${ }^{24}$. La cola y crines ondulantes, la testuz y el ala izquierda de Pegaso también imitan a Tempesta, al igual que la cabeza y el brazo tendido -que aquí se inviertede Medusa, colocada puritanamente boca abajo.

La sangre gorgónica, al tocar el suelo, se transforma en ramas de coral, según cita proveniente del episodio de la liberación de Andrómeda. Tras matar al cetáceo, Perseo decide lavarse las manos en la playa, dejando sobre un lecho de plantas marinas la cabeza de Medusa a fin de que no sufra daños. Las plantas, en contacto con ésta, se petrifican al instante, dando lugar al coral. $\mathrm{Su}$ presencia en la tela de Escobar es ajena a cualquier otra representación conocida y, por tanto, debe de obedecer a una voluntad simbólica deliberada que, en este caso, encuentra su explicación en una moralización de las Metamorfosis ${ }^{25}$ : Los vicios, como los corales en la mar, se multiplican sin medida si no son reprimidos por la virtud, que son los rayos solares, capaces de interrumpir con su calor el crecimiento coralino.

Antes de estudiar la siguiente pintura añadiremos otro testimonio que reafirma la glosa moral de esta serie y corrobora que la Historia de Perseo, en el Barroco español, se contemplaba como una especie de psicomaquia, más allá de la interpretación profana. Nada menos que las obras de Lope de Vega, extraordinariamente populares, recogen esta tradición, en ejemplos tan conocidos como la comedia El Perseo ${ }^{26}$. En ella, el héroe se dirige a Medusa con estas palabras: "Aqui estoy significando / la virtud, y tu cruel / el vicio... / Yo le sabre resistir / y cortare la cabeça... / Medusa, yo no he de ser / de los que el vicio cautiua» 27. Y al destruir a la Górgona, concluye: "Assi muerte al vicio doy / con la virtud celestial» 28.

La Liberación de Andrómeda (Fig. 3) es la escena más fiel a sus modelos grabados de todo el ciclo pictórico ${ }^{29}$. Tanto es así, que resulta mucho más consecuente apuntar sus diferencias que sus incuestionables similitudes con las estampas. Comenzando, pues, por la derecha, reparamos en varias figuras con atuendo militar que observan cómo Perseo se abalanza sobre el cetáceo.

\footnotetext{
21 Ibidem.

22 Nos referimos a la de Jorge de Bustamante, Las Transformaciones de Ovidio en lengua española..., Amberes, 1595, ff. 232 s., que incluye las alegorías de la traducción de Antonio Pérez Sigler, Salamanca, 1580, extraídas, a su vez, de las de Giuseppe Horologgi, elaboradas para las ediciones italianas traducidas por Anguillara. Acerca de las versiones de Viana y Bustamante, sigue siendo válido Schevill, R., Ovid and the Renascence in Spain, reimp., Hildesheim-Nueva York, 1971, pp. 143-73.

23 Cfr. Boccaccio, G., o.c., f. 76 v.

24 Madrigal, A. de, o.c., f. $102 \mathrm{v}$.

25 Ovidio, Metamorphoseos..., o.c., l.c.

26 Lope de Vega y Carpio, F., El Perseo, en Decimasexta parte de las comedias..., Madrid, 1621, ff. 108 v.-33. Lope describe a Medusa, con tono parecido, en La Andromeda, perteneciente a La Filomena con otras diversas Rimas, Prosas, y Versos, Madrid, 1621, ff. 91 v.-107 v, esp. f. 97 s.

27 Idem, El Perseo, o.c., f. 123 v.

28 Ibidem, f. 124.

29 Ovidio, La vita et metamorfoseo..., o.c., p. 73, y Tempesta, A., Metamorphoseon..., o.c., f. 40.
} 
Uno de los hombres señala hacia lo alto mientras conversa con otro que lleva coraza, casco con penacho y apoya el brazo izquierdo en un escudo oblongo. Este personaje destacado es, indudablemente, el rey Cefeo, padre de Andrómeda y esposo de Casiopea, que contemplaba, impotente, el sacrificio de su única hija al monstruo marino. Semejante calamidad era culpa de Casiopea, quien movida por la soberbia se había preciado de ser más bella que las propias Nereidas ${ }^{30}$. A petición de las injuriadas ninfas, Neptuno había enviado un gigantesco cetáceo que asolaría el reino a menos que, acatando los designios del oráculo, Andrómeda fuese inmolada a la bestia. Por Casiopea se entiende, en consecuencia, la soberbia, con el valor establecido, verbigracia, por Lope en La Andrómeda: «Si con los hombres es error culpado / el proceder con arrogante celo / Soberuia con los Dioses es pecado» ${ }^{31}$.

La desnudez de Andrómeda está ingenuamente velada por una melena interminable y un trozo de tela agitados por el viento. A sus pies se distinguen numerosas conchas y caracolas, que rememoran, nuevamente, los versos de Lope: «Pintad en vuestras peñas desiguales / a la diuina Andromeda desnuda / entre nacares, perlas y corales» ${ }^{32}$. Muy cerca, una leyenda anticipa el in-

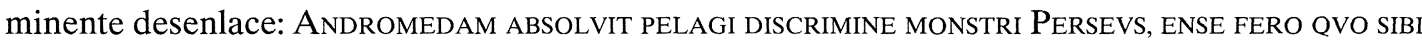
DVXIT EAm (Perseo libró a Andrómeda del peligro del monstruo marino, en feroz combate que la condujo hasta él). La joven doncella, ejemplo de piedad y de templanza para Conti ${ }^{33}$, no sólo será liberada por Perseo, sino que éste la desposará y la hará dichosa tras afrontar serenamente la desgracia. En la brumosa lejanía, detrás del peñasco al que está aún encadenada, se recorta la silueta de una ciudad que parece evocar la Sevilla del siglo xvir.

Perseo, a lomos de Pegaso, con un venablo y la égida de Palas como armas, arremete contra el monstruo que emerge del océano. El esquema general, extraído por entero de la ilustración de Bernardo Salomón (Fig. 7), fusiona la cabeza y las bridas del caballo de la lámina de Tempesta (Fig. 8) y se adereza con otros elemento como el vientre rayado y las alas membranosas de la criatura marina. Un detalle sugerente es el escudo con la cabeza de Medusa, que Ovidio no menciona como parte de este suceso ni aparece en las estampas citadas, pero que sí respaldan Conti ${ }^{34}$ e incluso Calderón, en sus Fortunas de Andrómeda y Perseo, donde el héroe obliga al cetáceo a mirar «en la azerada Luna / deste escudo, en quien impressa / quedò la faz de Medusa» ${ }^{35}$. Con esto se insinúa, de nuevo, el auxilio dispensado por la diosa de la sabiduría al virtuoso Perseo. Por otro lado, las Metamorfosis tampoco acreditan que Perseo montase a Pegaso e hiciera frente al monstruo con una lanza corta, sino que lo derrotó con ayuda de los talares y la espada de Mercurio. Esta adulteración, estudiada in extenso por Ruiz de Elvira ${ }^{36}$, fue sin embargo bien acogida, dada su mayor teatralidad, por Lope y Calderón ${ }^{37}$. Sea como fuere, la bestia, símbolo de todos los vicios y muerte de toda virtud ${ }^{38}$, termina hallando su fin ante Perseo.

30 Otra versión del relato, en la que Casiopea desafía a Juno a un certamen de belleza, puede leerse en Conti, N., o.c., p. 487

31 Lope de Vega y Carpio, F., La Andromeda, o.c., f. 101.

32 Idem, El Perseo, o.c., f. 130 v. El soneto 36 de Lope, transcrito por Vitoria, B. de: Primera parte del teatro de los dioses de la Gentilidad, Valencia, 1646, p. 287, evoca imágenes aún más cercanas al cuadro: «Atada al mar Andromeda, lloraua, / Los nacares abriendose al rocio... / Los cabellos al viento bullicioso / Que la cubra con ellos le rogauan..."

33 Cfr. Conti, N., o.c., l.c.

34 Ibidem, p. 423. Vid. también las disquisiciones al respecto de Madrigal, A. de., o.c., ff. $121 \mathrm{~s}$.

35 Calderón de la Barca, P., Fortvnas de Andromeda, y Perseo (s.l., s.d. [pero posterior al 18 de mayo de 1653 , fecha de su estreno en el Buen Retiro]) s. p. Otra mención en Arguijo, J. de, Soneto de Andrómeda y Perseo, en Poetas líricos de los siglos XvI y xvII. B.A.E., vol. 32, Madrid, 1854, p. 395.

36 Ruiz de Elvira, A., Mitología clásica, Madrid, 1975, p. 159, con bibliografía.

37 Lope de Vega y Carpio, F., El Perseo, o.c., f. 132 v, y Calderón de la Barca, P., o.c., l.c.

38 Ovidio, Metamorphoseos..., o.c., l.c. 


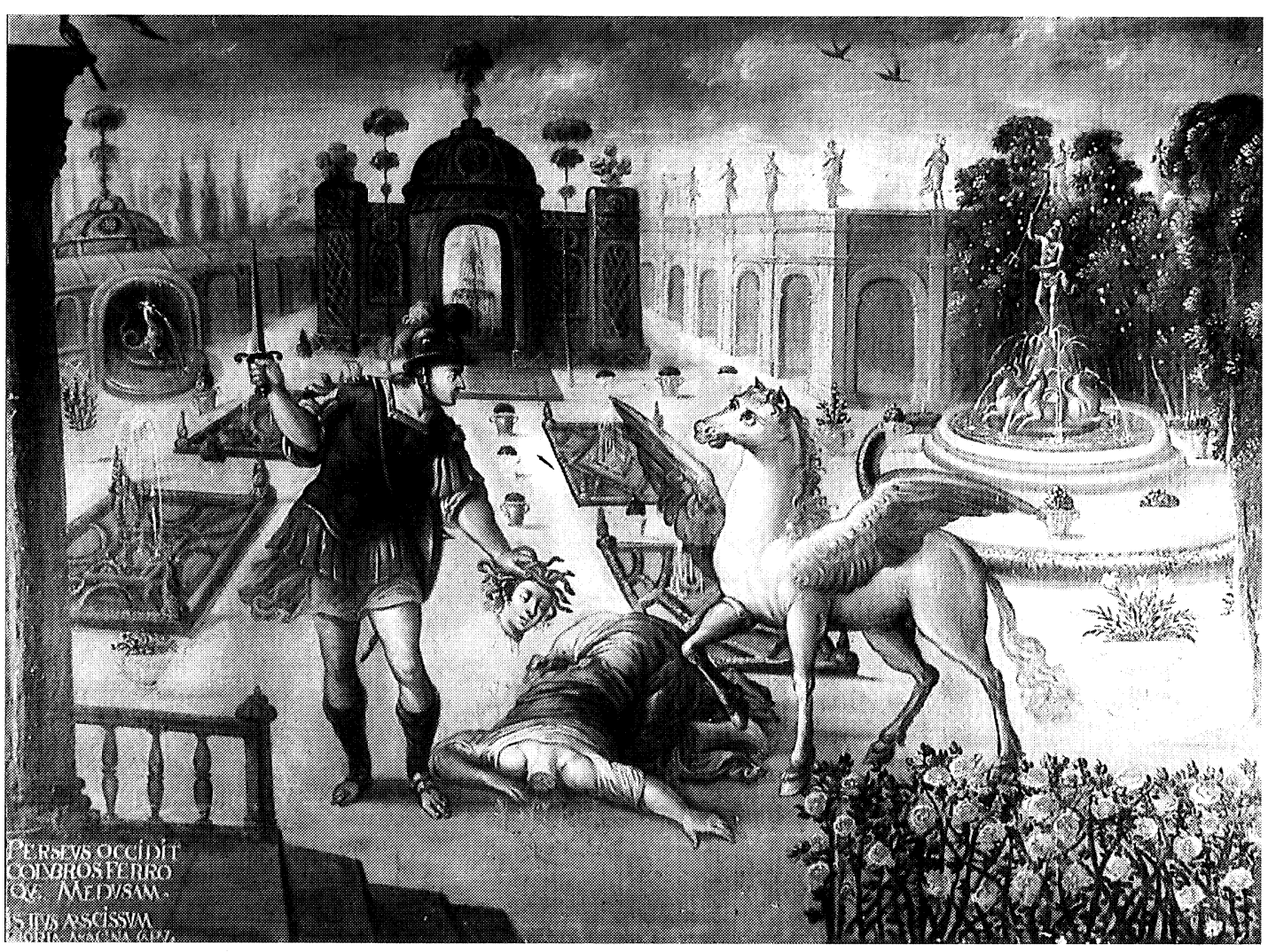

Fig. 2. Escobar, Perseo decapita a Medusa. Segovia, colección particular.

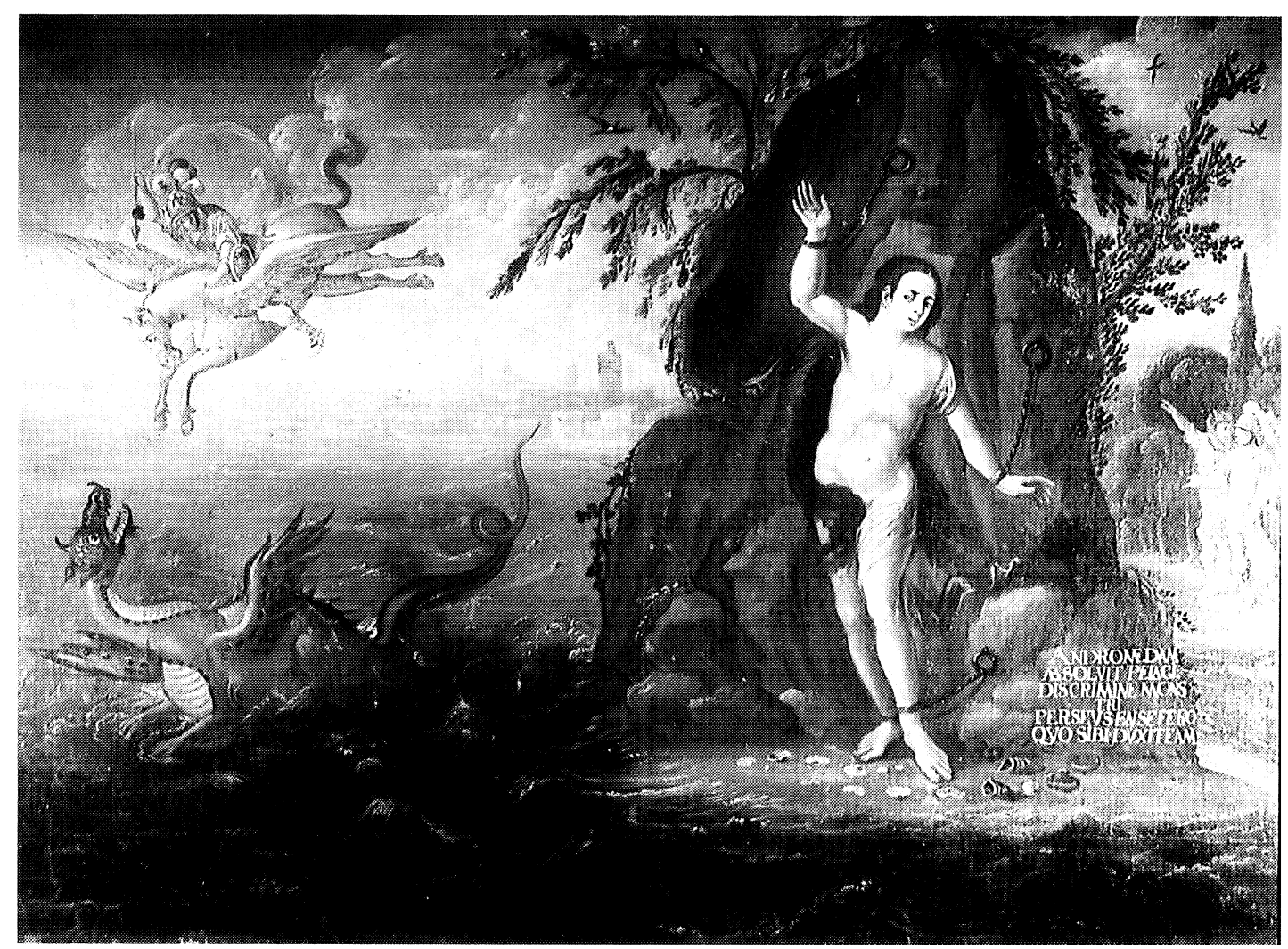

Fig. 3. Escobar, Liberación de Andrómeda. Segovia, colección particular. 

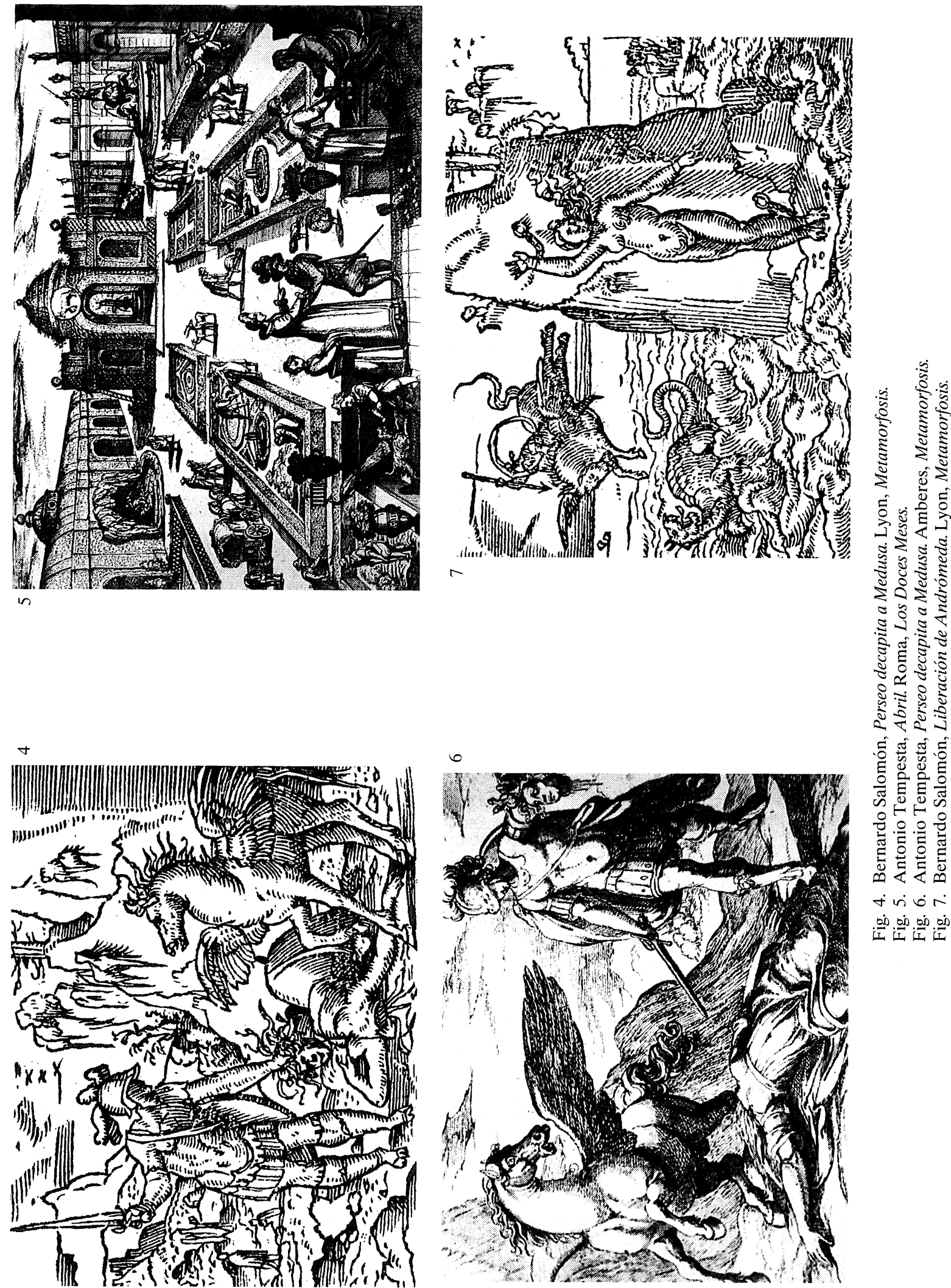
La serie pintada por Escobar se cierra con el Catasterismo de Perseo y Andrómeda (Fig. 9), esto es, la conversión de ambos en constelación. Se trata acaso de la única figuración explícita de este rarísimo tema en toda la pintura española, del que sin embargo se conocen referentes mitográficos. De esta forma, Boccaccio emplaza sus constelaciones al norte de la bóveda celeste, fundándose en la autoridad de Tulio y San Anselmo ${ }^{39}$; el Tostado, por su parte, prefiere apoyarse en Ptolomeo ${ }^{40}$; Baltasar de Vitoria, en último lugar, ofrece la exposición más cumplida en su Teatro de los dioses de la gentilidad, apelando, entre otros, a Plinio e Higinio, y afirmando que Perseo consta de "diez y siete» estrellas y «le pusieron en el cielo debaxo de la Vrsa menor", y que Andrómeda "tiene veynte, la qual està junto al signo de Piscis» ${ }^{41}$. Perseo, hijo de Júpiter y Dánae, fue catasterizado por su heroísmo, en tanto que Andrómeda, al transformarse en constelación, conservó la misma disposición que mantuvo durante su encadenamiento, con los brazos en forma de cruz.

Paradójicamente, Ovidio no hace la menor alusión a este prodigio, acarreando con ello la carencia total de representaciones del tema en las ediciones grabadas de las Metamorfosis. Escobar, por tal motivo, hubo de inspirarse en un episodio formalmente similar, el Rapto de Oritía por el viento Bóreas (Fig. 10), que estaba ilustrado en las ediciones de Lyon ${ }^{42}$, pero no en la de Tempesta. De hecho, este último se basó en la viñeta de Salomón para confeccionar su Rapto de Deyanira ${ }^{43}$ (Fig. 11), lámina que no pasó desapercibida al sevillano y que asimismo empleó para, entre otras cosas más manifiestas, dotar a Andrómeda de la consabida postura de los brazos en cruz. Las singulares alas de Perseo denotan, en este contexto, su condición de alma inmortal, como razonaremos más abajo ${ }^{44}$.

El paisaje reproduce tipologías entresacadas de la segunda serie de Los doce meses y, en especial, de los Paisajes con figuras de 1592, grabados ambos - no podía ser de otro modo- por Tempesta. Algunos animales corren inquietos entre la arboleda, apreciándose sin dificultad un ciervo, un faisán, un jabalí y dos ciervas, cuya presencia, si bien congruente, resulta difícilmente descifrable. Parte de esta antificiosidad puede encontrar justificación a la luz del alegorismo demandado a toda la Historia de Perseo, donde convienen a la coherencia programática las imágenes del venado, el faisán, o el jabalí en su acepción tradicional de encarnaciones de la lujuria y la lascivia ${ }^{45}$.

Queda entonces por elucidar el sentido de la pareja de ciervas del fondo, que no reflejan esta iconografía y que precisan de una clave para su comprensión. La respuesta se encuentra a su lado en forma de manzana dorada, intencionadamente desproporcionada para indicar su carácter simbólico en referencia a un hecho de la vida de Perseo que, de esta guisa, aparece de manera elíptica. Nos referimos al robo de las manzanas de las Hespérides, atribuido a Perseo, en lugar de a Hércules, por Ovidio. El poeta narra cómo, después de acabar con Medusa, Perseo inicia un dilatado periplo que le lleva hasta el reino de Atlas, dueño del huerto de las manzanas de oro. Perseo le pide acogida, a lo que el titán, advertido por el oráculo de Temis de que recelase de un hijo de Júpiter que le robaría el oro, se niega obstinadamente. De malas maneras intenta expul-

39 Boccacio, G., o.c., f. 89.

40 Madrigal, A. de., o.c., ff. $96 \mathrm{v}, 104 \mathrm{v}, 202$.

41 Vitoria, B. de, o.c., pp. 195, 287 s.

42 Ovidio, La vita et metamorfoseo..., o.c., p. 94.

43 Tempesta, A., Metamorphoseon..., o.c., f. 83.

44 Cfr. El Alma racional y felizy la Inmortalidad, en Ripa, C., Iconologia, Roma, 1603, pp. 21 s., 223 resp.

45 La condición lasciva del ciervo macho ya la señalan Aristóteles y Plinio, como demuestra Mariño Ferro, X. R., El simbolismo animal, Madrid, 1996, p. 92. Otra explicación, también muy completa, en Tervarent, G. de, Attributes et symboles dans l'art profane (1450-1600), Ginebra, 1959, pp. 65-8. Para el faisán como símbolo de la lujuria y la lascivia, cfr. Vries, A. de, Dictionary of Symbols and Imaginery, 3. ${ }^{a}$ reimp., Amsterdam, 1984, pp. 363 s., y Mariño Ferro, X. R., o.c., p. 161, que igualmente analiza el jabalí como atributo de la lujuria en la p. 207. 


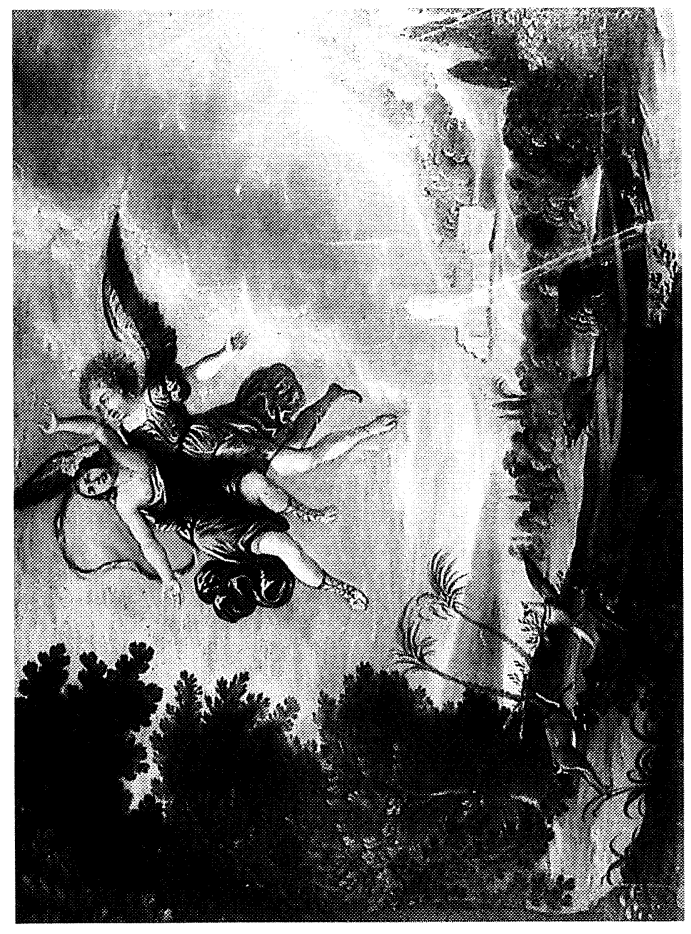

9

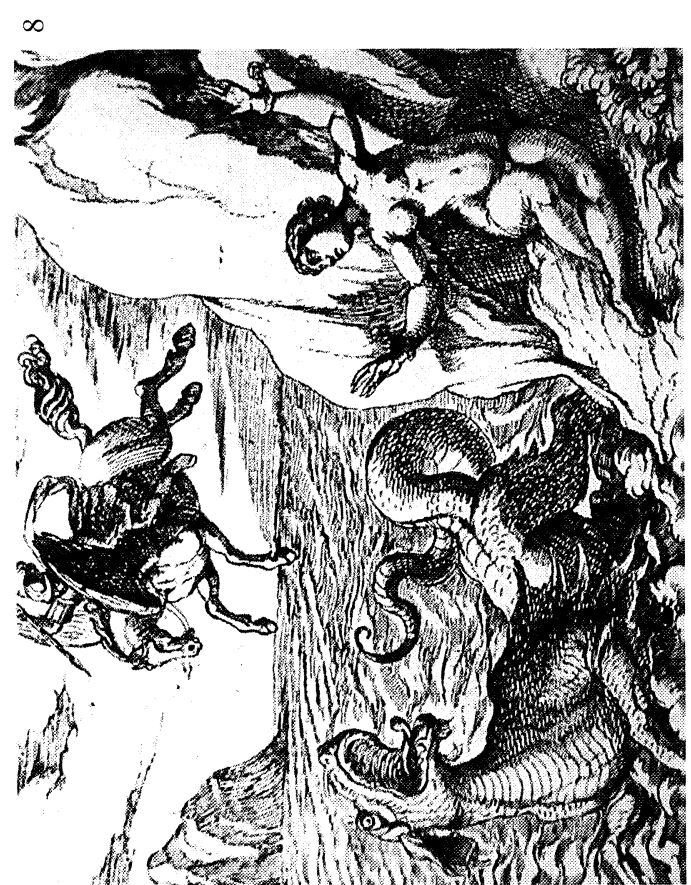

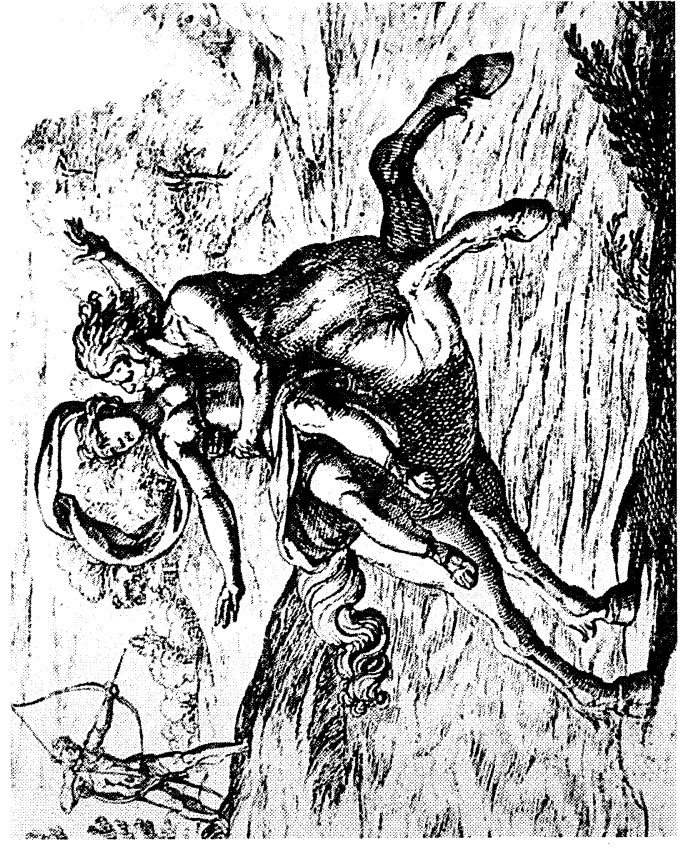

$=$

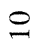
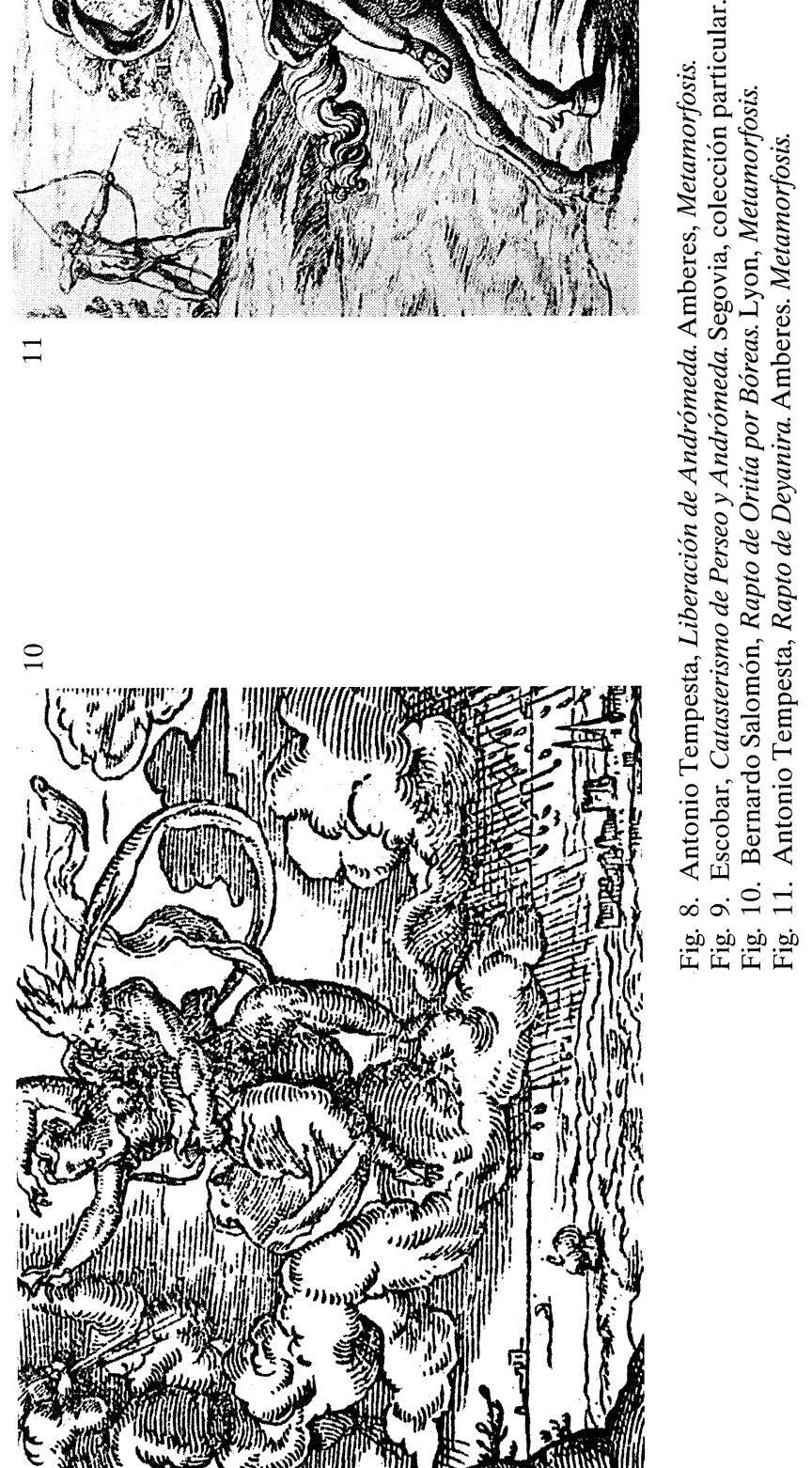
sar al héroe, y éste responde a la provocación exhibiendo la cabeza de la Górgona, que petrifica a Atlas y lo convierte en la cordillera del mismo nombre. Esta visión del mito la complica aún más Boccaccio al sugerir que, según algunos, las Hespérides no eran hijas de Héspero, sino de Atlas, y que éstas eran en realidad las Górgonas ${ }^{46}$. Pérez de Moya intenta, sin resultado, esclarecer esta confusión, declarando que no hubo un solo Hércules «mas vuo muchos... y todos los historiadores de aquel tiempo escriuieron de muchos Hercules, de los quales Perseo fue vno de los famosos que vuo en su tiempo" ${ }^{47}$. En tal estado de cosas, no es de extrañar que pudiera solaparse una fábula más, de la de la captura de la cierva de pies de bronce que Hércules acosó hasta el país de-los hiperbóreos, lugar legendario donde los manzanos maduraban con asombrosa rapidez y cuyos pobladores disfrutaban de una vida casi imperecedera. La búsqueda de la manzana de oro se constituía de esta suerte en búsqueda de la inmortalidad.

Una lectura complementaria entiende el huerto como el lugar de estudio y las manzanas doradas como los frutos de dicha labor, de acuerdo con las propias Metamorfosis ${ }^{48}$. Lope de Vega amplía esta idea y la pone en boca de Atlas, que se excusa ante Perseo por no darle alojamiento: «Huyendo el vulgo profano / a mis libros, me retiro, / los amigos verdaderos / que yo tengo son mis libros. / No doy a nadie en mi casa / lugar, porque no permito / que mis estudios perturben / aun vassallos, y vezinos» 49 .

Con esto finaliza la serie de la Historia de Perseo y se revela su significación colectiva, otra vez formulada por Boccaccio ${ }^{50}$, según la cual el héroe prudente triunfa sobre el vicio y asciende a la virtud, igual que la mente piadosa, despreciados los placeres mundanos, alcanza la vida eterna. Y aunque no sea más que un reflejo de esta conclusión, permítasenos recordar a León Hebreo, cuyos Diálogos de amor resumen, con tanta claridad como belleza, todo lo antes contado: «Sinifica... Perseo moralmente el honbre prudente hijo de Iupiter, dotado de sus uirtudes, el qual matando al uicio baxo y terestre... subio en el cielo de la uirtud», como «tanbien... la mente humana..., matando y uenciendo la terestridad..., subio a entender las cosas celestiales altas y eternas en la qual especulacion consiste la perfecion humana» ${ }^{51}$.

\footnotetext{
46 Boccaccio, G., o.c., f. 33 v.

47 Pérez de Moya, J., o.c., f. 189 v., plagiando a Madrigal, A. de, o.c., lib. 3, f. 31.

48 Ovidio, Metamorphoseos..., o.c., l. c.

49 Lope de Vega y Carpio, F., El Perseo, o.c., f. 125 v.

50 Boccaccio, G., o.c., f. 8 v.

51 Hebreo, L., Dialogos de amor, Venecia, 1568, f. 28 v.
} 